\title{
DIÁLOGO DE CORTES: A INFLUENCIA DA CORTE INTERAMERICANA DE DIREITOS HUMANOS EM MATÉRIA DE EXECUÇÃO PENAL NO SUPREMO TRIBUNAL FEDERAL
}

\author{
Antonio Carlos Moni de Oliveira ${ }^{1}$ \\ Beatriz Corrêa Camargo ${ }^{2}$ \\ Cândice Lisbôa Alves ${ }^{3}$
}

\section{Resumo}

O artigo se propôs a avaliar a influência das decisões da Corte Interamericana de Direitos Humanos (Corte IDH) no Supremo Tribunal Federal (STF). O tema de análise escolhido foi a execução da pena privativa de liberdade, uma área em que o Brasil tem recebido condenações e advertências em âmbito internacional. Buscou-se demonstrar a necessidade de maior diálogo do STF com a Corte IDH, cuja produção muito tem a contribuir para o avanço da salvaguarda dos Direitos Humanos nas prisões brasileiras. A pesquisa realizada foi bibliográfica e exploratória, e o método de abordagem foi o indutivo. A coleta de jurisprudência seguiu padrões quantitativos e qualitativos.

Palavras-chave: Corte Interamericana de Direitos Humanos; Supremo Tribunal Federal; diálogo das cortes; cárcere; encarcerado; Direitos Humanos; direitos fundamentais; jurisprudência.

\footnotetext{
${ }^{1}$ Mestrando na Faculdade de Direito da Universidade Federal de Uberlândia. E-mail: antonio.moni@ufu.br

${ }^{2}$ Professora de Direito Penal Universidade Federal de Uberlândia nos cursos de graduação e mestrado em Direito. Pós-doutora em Direito Penal pela Universidade de Bonn (2018). Pesquisadora Visitante na Universidade de Halle (2017) e no Instituto MaxPlanck para Direito Penal Internacional e Estrangeiro (2008). Doutora em Direito Penal pela Universidade de São Paulo (2015).E-mail: beatrizcamargo@ufu.br

${ }^{3}$ Professora de Direito Constitucional na Universidade Federal de Uberlândia nos cursos de graduação e mestrado em Direito. Doutora em Direito Público pela Pontifícia Universidade Católica de Minas Gerais. E-mail: candicelisboalves.prof@gmail.com
} 


\section{INTRODUÇÃO}

No âmbito internacional de proteção dos direitos humanos, constitui importante conquista a criação de organismos desenvolvidos para exercer atividade tipicamente jurisdicional. Na realidade latino-americana, o protagonismo para tanto é conferido à corte interamericana de direitos humanos (corte idh).

O movimento das nações no sentido de reconhecer a atuação das Cortes Internacionais de Direitos Humanos enfrenta dificuldades diversas. Sem sombra de dúvidas, um dos obstáculos mais graves para a proteção dos Direitos Humanos é o fato de que a soberania dos Estados normalmente impõe graves restrições à obrigatoriedade de se observar internamente os compromissos assumidos em âmbito internacional, criando-se barreiras, igualmente, à ingerência de órgãos externos para investigar e punir as violações desses direitos (NIÑO, 1989, p. 5).

No entanto, é possível afirmar que a premissa para a atuação das Cortes Internacionais possui espectro mais amplo e profundo. Em realidade, ela se baseia, sobretudo, na constatação quanto à insuficiência da jurisdição nacional para a proteção dos Direitos Humanos, evidenciando-se que por vezes a própria perspectiva interna poderia insular um direito humano do ponto de vista teórico, afastando sua previsão normativa das demandas da vida real.

Desta sorte, além de ser responsável pela averiguação de violações aos direitos estabelecidos pela Convenção Americana de Direitos Humanos (CADH), conhecida como Pacto de São José da Costa Rica, a Corte ainda possui a função de concretizar a extensão e o conteúdo dos instrumentos normativos que compõem o Sistema Interamericano de Direitos Humanos, nos termos do que dispõe a própria Convenção Americana, em seu artigo 62,3.

Nada mais atual, então, que pensar na necessidade de um diálogo entre as cortes nacionais e internacionais, e na permeabilidade das mesmas quando a tarefa em comum entre elas é a concretização e a realização dos Direitos Humanos (RAMOS, 2016, p. 349).

Nesse sentido, o presente artigo se propõe a analisar a influência das decisões da Corte Interamericana de Direitos Humanos (Corte IDH) no Supremo Tribunal Federal (STF), a partir de uma pesquisa exploratória. Para a referida análise escolheu-se o tema das violações de Direitos Humanos nas prisões brasileiras, realidade que nosso país tem prorrogado e agravado. Essa situação resultou em condenações e advertências ao Brasil perante a Organização dos Estados Americanos e de maneira lenta e gradual tem mobilizado o sistema judiciário brasileiro em prol de uma resposta. Esse campo de jurisdição em favor dos Direitos Humanos se mostra particularmente interessante devido à extensa jurisprudência da Corte IDH no que diz respeito à execução da pena privativa de liberdade, onde se apresentam diversos critérios e requisitos para a proteção dos Direitos Humanos dos 
prisioneiros nos Estados signatários.

A hipótese de trabalho é a de uma escuta disfuncional entre o Supremo Tribunal Federal e a Corte Interamericana de Direitos Humanos. A comprovação da hipótese foi desenvolvida a partir do estudo de três casos selecionados na jurisprudência do STF.

\section{O DIÁlOgo POSSÍVEL E NECESSÁRIO COM A CORTE INTERAMERICANA DE DIREITOS HUMANOS}

A ideia de diálogo entre cortes nacionais e internacionais se refere a um estágio desejável de cooperação entre a jurisdição interna dos países na observância de normas e direitos garantidos internacionalmente e a jurisdição dos organismos internacionais direcionadas no mesmo propósito.

Nesse sentido, é preciso reconhecer que entre o Supremo Tribunal Federal e a Corte IDH pode acontecer um movimento não apenas de acoplamento, como também de repulsa. Decisões jurídicas conflitantes fazem parte desse processo, tendo-se em vista que cada vez mais temas podem ser submetidos tanto a uma quanto a outra jurisdição. A esse respeito, cabe lembrar o caso da Guerra do Araguaia, ou caso Gomes Lund vs. Brasil, em relação ao qual Sarmento (2015, p. 4) menciona a decisão divergente sobre a lei nacional de anistia no Brasil, que foi julgada válida pelo STF, não obstante ter sido rechaçada pela Corte IDH.

Em termos teóricos, o problema do diálogo é percebido no contexto de incentivo à deliberação pública (LINARES, 2008, p. 488), o que perpassaria por três fases possíveis: argumento, resposta e réplica. Estas fases são pensadas para o diálogo entre Corte e Congresso, porém, a estrutura se adequa ao diálogo ente cortes, objeto de análise deste artigo.

Ao analisar os tipos de diálogos entre Cortes Constitucionais e Congresso, Linares esclarece que a noção de um diálogo democrático deve envolver alguns elementos fundamentais. Primeiramente, o fato de que cada parte ofereça razões para manter seu argumento, as quais possam ser entendidas e debatidas pela outra parte (LINARES, 2008, p. 513). Ou seja, parte-se da existência de um desacordo entre pessoas que se veem obrigadas a manifestar argumentos aptos a convencer a parte contrária. Em segundo lugar apresenta-se a premissa de que o diálogo seja livre e se baseie em razões justificadas ou justificáveis em termos argumentativos (LINARES, 2008, p. 513). Indo além, para que o diálogo seja classificado como democrático, é necessário, ademais, que as partes tenham poder de fala em condições de igualdade, o que resgata o direito à participação e à inclusão, não apenas do ponto de vista formal, mas substancial (LINARES, 2008, p. 513), pois apenas assim se pode desenvolver uma relação comunicativa real. Do ponto de vista ideal, é relevante que estes pontos de vista tenham a mesma ordem de importância, ou sejam levados em consideração da mesma maneira quando da decisão final. É preciso, 
portanto, mais do que simplesmente ter oportunidade de dizer, requerendo-se que os argumentos lançados sejam efetivamente considerados e trabalhados na decisão final.

Pensando em um diálogo de Cortes, parte-se, então, do pressuposto de que as razões trabalhadas como argumento nas decisões da Corte Interamericana de Direitos Humanos deveriam ser refinadas no Supremo Tribunal Federal em um sentido de afirmação ou afastamento dos argumentos levantados. Em outras palavras, exigir-se-ia duas situações específicas: i. menção aos casos paradigmáticos decididos na Corte Interamericana; ii; que os argumentos utilizados na decisão da Corte fossem novamente debatidos no STF com a finalidade de pacificar as razões de sua aplicação ou não no Direito nacional, e, assim, construir uma coerência interna quanto ao direito em análise não apenas no cenário nacional, mas que entrelaçasse o Brasil com a postura da Corte, garantindo certeza e segurança jurídica e o respeito aos Direitos Humanos.

\section{As decisões da Corte IDH em matéria de execução da pena}

Desde há muito tempo a Corte Interamericana de Direitos Humanos se ocupa de questões relacionadas ao problema carcerário no continente americano. Especial atenção merecem, neste tocante, os critérios que oferece sobre a definição desses direitos e sobre quando ocorreria exatamente uma violação aos Direitos Humanos no âmbito da Execução Penal. Algumas temáticas podem ser mencionadas nesse sentido.

Comecemos pelo problema da superlotação carcerária. Sobre esse assunto, a Corte IDH já se pronunciou em diversas oportunidades, afirmando que, quando o número excessivo de presos se protrai no tempo, esse estado constitui, por si só, uma violação de Direitos Humanos, devido aos riscos e lesões gerados sobre a integridade pessoal dos detentos. Essa questão ficou bastante clara no Caso López Álvarez vs. Honduras De maneira idêntica ao que se verifica na realidade brasileira, a Corte IDH considerou que

[...] durante a detenção do senhor Alfredo López Álvares nos centros penais de Tela e de Támara havia superpopulação carcerária; a presumida vítima estava em situação de superlotação permanente; ficou numa cela reduzida, habitada por numerosos reclusos; teve que dormir no chão durante um longo período; não contou com uma alimentação adequada nem água potável, nem dispôs de condições higiênicas indispensáveis (tradução nossa) (ORGANIZAÇÃO DOS ESTADOS AMERICANOS, 2014) .

\footnotetext{
${ }^{4}$ A sentença de 01 de fevereiro de 2006 versa sobre o caso do senhor Lopez Alvarez, que ficou preso provisoriamente durante 6 anos e quatro meses em locais insalubres e superlotados, nos quais não existia qualquer separação entre os processados e os condenados. Ao final do processo criminal, acabou sendo absolvido, mas havia sido gravemente afetado pelos danos decorrentes da prisão.

${ }^{5}$ No original: "Está probado que durante la detención del señor Alfredo López Álvarez en los centros penales de Tela y de Támara había sobrepoblación carcelaria; la presunta víctima se encontraba en situación de hacinamiento permanente; estuvo en una celda reducida, habitada por numerosos reclusos; tuvo que dormir en el suelo durante un largo período; no contó con una alimentación
} 
Desta maneira, pode-se afirmar que a manifestação do STF nos casos a seguir analisados desconsiderou a oportunidade de seguir a jurisprudência da Corte Interamericana para declarar a inconstitucionalidade da própria superlotação carcerária. Em relação ao tema, espera-se que o Supremo se posicione, já que a questão foi suscitada pela petição inicial da ADPF 347 (BRASIL, 2016a, p. 13), onde se trouxe o exemplo estadunidense, no qual os magistrados da Califórnia impuseram ao Executivo a obrigação de elaborar um plano para reduzir a superlotação, para no máximo 137,5\% da capacidade das prisões do estado. Em razão do fato de a ação estar ainda em fase inicial, é compreensível o não posicionamento do STF a esse respeito. Porém, na decisão de mérito este posicionamento é devido e aguardado.

O mesmo vale para o problema da falta de assistência jurídica para os encarcerados. Tratando de situação mais delicada, por envolver menores de idade, a Corte IDH, na Opinião Consultiva OC-21/14 de 19 de agosto de 2014 (ORGANIZAÇÃO DOS ESTADOS AMERICANOS, 2014), decidiu que é dever do Estado garantir a todos os adolescentes o direito à defesa através de serviços estatais de representação legal, ainda que se trate apenas de uma restrição administrativa da liberdade de locomoção por questões de ordem migratória ${ }^{6}$. Nesse sentido, vale lembrar que segundo a Corte Interamericana, a assistência jurídica é aquela exercida por profissional do direito, voltada a satisfazer a defesa técnica com a finalidade de assessorar a pessoa submetida ao processo judicial.

Sobretudo, é em relação às condições de infraestrutura da prisão que a Corte IDH oferece farto conjunto de parâmetros, bastante concretos, com a finalidade de definir os limites do respeito aos Direitos Humanos das pessoas privadas de liberdade. No Caso Montero Aranguren e outros (Retén de Catia) vs. Venezuela, decidido em 5 de julho de 2006, a Corte preceitua que o presídio superlotado - e, portanto, lesivo aos Direitos Humanos se caracteriza por um alojamento anti-higiênico e reduzido, sem privacidade para o sujeito realizar as atividades básicas, como o uso das facilidades sanitárias (ORGANIZAÇÃO DOS ESTADOS AMERICANOS, 2016).

Ademais, a prisão contraria o direito à humanidade quando, devido ao número de internos, não oferece atividades fora da cela de maneira razoável, quando os serviços de saúde estão sobrecarregados, quando há um aumento da tensão no ambiente, e, por conseguinte, maior violência entre os prisioneiros e os agentes penitenciários. Segundo a Corte IDH, essa lista exemplifica indicativos de que a unidade prisional estaria superlotada. Em sua análise, a própria Corte Interamericana dialoga, por fim, com o Comitê Europeu para a Prevenção de Tortura e de Penas ou Tratos Desumanos ou Degradantes, para determinar como razoável o espaço de $7 \mathrm{~m}^{2}$ por preso. Fazendo referência ao Sistema Europeu de Proteção dos Direitos Humanos, a Corte IDH aponta para decisão da Corte Europeia de Direitos Humanos na qual restou decidido que um espaço de

adecuada ni agua potable, ni dispuso de condiciones higiénicas indispensables”.

${ }^{6}$ Trata-se de consulta feita pela Argentina, Brasil, Paraguai e Uruguai sobre crianças imigrantes. 
$2 \mathrm{~m}^{2}$ por preso não era aceitável. Ademais, a Corte Interamericana assimila a argumentação da Corte Europeia quando esta conclui que numa cela de $16,65 \mathrm{~m}^{2}$ em que vivem 10 presos verifica-se desumana falta de espaço (ORGANIZAÇÃO DOS ESTADOS AMERICANOS, 2014).

Em outras oportunidades, a Corte Interamericana se pronunciou ainda sobre a necessidade de ventilação e luz natural na cela, enquanto condição indispensável para a dignidade humana (Caso Tibi vs. Ecuador, sentença de 7 de setembro de 2004), assim como sobre a necessidade de cada preso ter uma cama na qual repousar, a exemplo do que foi decidido no Caso Fleury e outros vs. Haití, na sentença de 23 de novembro de 2011 (ORGANIZAÇÃO DOS ESTADOS AMERICANOS, 2014).

\section{Escuta (dis)funcional}

No tocante ao tema da execução criminal, conforme pudemos constatar em nossa pesquisa, a referência do Supremo Tribunal Federal à jurisprudência da Corte Interamericana de Direitos é escassa. De modo geral, não se pode afirmar existir aqui um verdadeiro diálogo com as diretivas firmadas pela Corte IDH, na medida em que falta para isso o reconhecimento, por parte do STF, de que as decisões concretas da Corte Interamericana são vinculantes à sua própria atuação jurisdicional .

Em outras palavras: não basta ouvir. É preciso compreender o outro como interlocutor.

Assim, o conceito de diálogo não exige aderência a absolutamente tudo o que for dito pelo interlocutor. Entretanto, na medida em que o Supremo Tribunal Federal, como órgão de jurisdição nacional, se submete às normativas e à jurisdição estabelecidas em âmbito internacional, torna-se imprescindível para ele um esforço argumentativo no sentido de se justificar perante à sociedade brasileira e internacional quando for o caso de desvio em suas decisões relativamente à interpretação dada pela Corte IDH na proteção dos Direitos Humanos (RAMOS, 2016, p. 351).

Sem observância a essa premissa, a escuta do que diz a Corte IDH fica disfuncional. Importante salientar nesse contexto que a interação não deve se limitar aos órgãos de jurisdição nacional. Em realidade, uma vez que se encontram todos envolvidos na mesma missão de assegurar o respeito à dignidade humana, o diálogo deve se estender de maneira igual aos membros do poder Legislativo e Executivo, incluindo-se o Ministério Público, o Conselho Federal da Ordem dos Advogados e o Conselho Nacional de Justiça (RAMOS, 2016, p. 349).

Desta maneira, podemos concluir com André Carvalho Ramos, que

[...] o Direito Internacional dos Direitos Humanos no Brasil está manco: formalmente, o Brasil está plenamente engajado; na aplicação prática, há um total silêncio sobre a interpretação dada pelo próprio Direito Internacional (na voz de seus intérpretes autênticos, como, por exemplo, a Corte Interamericana de Direitos Humanos), o que pode gerar a 
responsabilização internacional do Brasil por violação de Direitos Humanos (RAMOS, 2016, p. 350).

Por isso, ainda que o Supremo Tribunal Federal chegue a reconhecer em caráter definitivo o Estado de Coisas Inconstitucional, essa decisão continua sendo uma postura extremamente acanhada. Espera-se que na sede da ADPF 347 o STF dê um passo além e venha a se servir do entendimento sedimentado na Corte IDH para estabelecer os parâmetros e os critérios através dos quais se estabelecem as violações aos Direitos Humanos, assim como, o que fazer a partir disso.

\section{DELIMITAÇÃO DA PESQUISA JURISPRUDENCIAL}

Nosso estudo limitou a pesquisa de jurisprudência ao Supremo Tribunal Federal (STF), cujo protagonismo em razão da matéria de proteção dos Direitos Humanos é o mais evidente, principalmente após o que restou decidido no Recurso Especial 466.343/SP, de acordo com o qual os Tratados de Direitos Humanos ocupariam status supralegal no ordenamento nacional.

Como critério de pesquisa no site de busca de jurisprudência do Supremo Tribunal Federal foram utilizados os termos "corte" "interamericana" "execução" "penal", interligados pelo operador booleano "AND". Primeiramente, foram encontrados 15 julgados. Deste universo, foram selecionados três julgados para uma análise mais aprofundada, nos quais a violação dos direitos fundamentais no cárcere era mais flagrante e o diálogo com a Corte IDH se mostrou mais necessário: o Recurso Extraordinário 592.581/RS, o Recurso Extraordinário 580.252/MS, e a Ação de Descumprimento de Preceito Fundamental 347 (ADPF 347). A seleção dessas decisões foi feita conforme critérios qualitativos, por terem por objeto questões relacionadas à Execução Penal e aos Direitos Humanos.

Uma das decisões não guardava qualquer relação com o tema da execução penal. Nos demais julgados , o que se percebeu foi a ausência de questões relacionadas diretamente à violação de direitos no cárcere, a exemplo da possibilidade de execução de pena antes do trânsito em julgado da sentença penal condenatória. Em um dos casos em que se discutiu o marco temporal para o trânsito em julgado, a citação à Corte Interamericana é feita apenas no voto vencido, do Ministro Celso de Mello (BRASIL, 2016c).

Algumas decisões tiveram por objeto a violação ao duplo grau de jurisdição relativamente às ações penais originárias dos tribunais superiores, mais especificamente as que giraram em torno da AP 470 (cf. BRASIL, 2013b). Em outro contexto, se questionava a transferência do preso para um presídio de segurança máxima sem a observância do devido processo legal, sendo que a decisão da Corte IDH constituiu o argumento destinado a justificar a transferência do preso considerado perigoso, buscando-se evitar outras rebeliões. Ou seja: neste último 
caso, em lugar de garantir direitos, a jurisprudência interamericana foi empregada com a finalidade de legitimar uma atuação contrária aos parâmetros estabelecidos pela legislação processual aplicável (BRASIL, 2013c). Por fim, a corte brasileira também faz menção à jurisprudência da Corte interamericana quando aduz pela necessidade de se impedir que um civil seja submetido a tribunal militar, como no HC 110185 (BRASIL, 2013d) e no HC 110237 (BRASIL, 2013e).

Todas essas questões possuem consequências para a execução penal. Todavia, elas escapam à análise que nos interessa na medida em que não têm por objeto específico as condições desumanas nas prisões brasileiras. De modo geral, elas apenas tangenciam o problema relacionado à inefetividade dos direitos daqueles que estão privados da liberdade.

Conforme se verá, as três decisões analisadas a seguir demonstram a necessidade de um maior grau de diálogo do Supremo Tribunal Federal com o que vem decidindo a Corte Interamericana de Direitos Humanos no âmbito da execução penal, principalmente no que concerne aos direitos fundamentais do encarcerado.

De todo modo, o conjunto das quinze decisões encontradas evidencia tratar-se de uma preocupação relativamente recente quando se considera o período de vigência de jurisdição da Corte IDH no Brasil. Do universo selecionado, o julgado mais antigo do STF que faz referência à Corte IDH em matéria de execução penal data do ano de 2008.

\section{RECURSO EXTRAORDINÁRIO 592.581/RS}

O Recurso Extraordinário 592.581/RS tem por objeto a possibilidade, ou impossibilidade, de se impor, através de decisão jurisdicional, à Administração Pública a obrigação de fazer, consistente em reformar estabelecimento prisional, com a finalidade de se garantirem os direitos fundamentais das pessoas privadas de liberdade.

O conteúdo fático é a violação ao direito à integridade física e psíquica dos segregados, que na situação concreta corriam risco de vida no estabelecimento prisional em que se encontravam. Para se ter noção das dimensões envolvidas, um dos internos chegou a falecer em decorrência do choque originado das instalações elétricas precárias do local.

Trata-se de uma decisão importante no cenário brasileiro. O julgamento desse Recurso Extraordinário teve como decorrência a elaboração da Tese n 200 do Supremo Tribunal Federal. De acordo com esse enunciado, a corte considera lícito que Judiciário imponha à Administração Pública a obrigação de fazer consistente na promoção de medidas determinadas ou na execução de obras emergenciais em estabelecimentos penais, a fim de concretizar o postulado da dignidade da pessoa humana e assegurar aos detentos o respeito à sua 
integridade física e moral (BRASIL, 2016b).

Em seu voto, o Relator Ministro Ricardo Lewandowski faz referência ao estado precário das prisões brasileiras, lembrando que o Brasil já sofreu condenações pela Corte Interamericana nesse sentido (BRASIL, 2016b).

Aqui, utiliza-se da força normativa dos mecanismos internacionais de proteção aos Direitos Humanos, ao frisar que a União assume as obrigações decorrentes dos Direitos Humanos salvaguardados pelos pactos internacionais, trazendo para o debate o conteúdo de decisões nas quais o Brasil foi condenado pela Corte IDH em decorrência da violação dos Direitos Humanos no cárcere.

Além disso, o relator abre um tópico específico para tratar das decisões internacionais que disciplinam a matéria. Neste ponto, as sanções impostas ao Brasil funcionam como recurso argumentativo acerca das condições carcerárias. Desta sorte, o relator discorre sobre o contexto de envolvimento do Brasil em âmbito internacional nesta matéria:

Recordo, ainda, que, em consequência da reiterada violação aos Direitos Humanos dos presos no Brasil, já foram ajuizados contra o País diversos processos perante a Comissão e a Corte Interamericana de Direitos Humanos. Dentre eles, o de maior repercussão é aquele que envolve a denúncia de mortes e maus-tratos de detentos no Presídio José Mário Alves da Silva, conhecido como "Urso Branco", situado em Porto Velho/RO. Tal caso é considerado internacionalmente um verdadeiro paradigma do descaso com que as autoridades brasileiras tratam do sistema penitenciário. No âmbito interno, rememoro, ele deu ensejo a pedido de intervenção federal no Estado nesta Suprema Corte. Lamentavelmente, a situação do Urso Branco não é o único exemplo de crítica internacional à violação de direitos dos reclusos em nossas penitenciárias. A Corte Interamericana apreciou também a situação do Complexo do Tatuapé - FEBEM, em São Paulo/SP, da Penitenciária Dr. Sebastião Martins Silveira, em Araraquara/SP, e da Unidade de Internação Socioeducativa, em Cariacica/ES, determinando medidas a serem cumpridas pelo Estado brasileiro voltadas à proteção da vida e da integridade física dos reclusos e daqueles que trabalham ou frequentam aqueles estabelecimentos" (BRASIL, 2016b).

O Recurso Especial 592.581/RS versa sobre a imposição de deveres ao Estado, assim como a ADPF 347, cuja análise será feita mais adiante. Nesse sentido, o Supremo impõe condutas à Administração Pública, como a construção de presídios, e ao próprio Judiciário, no sentido de buscarem a concretização dos Direitos Humanos no cárcere. Todavia, a tônica dos dois julgados parece ser direcionada muito mais a uma discussão sobre a ingerência do Judiciário em políticas públicas do que, de fato, à concreção dos direitos fundamentais do encarcerado.

Em relação ao RE 592.581/RS, embora se note um diálogo maior com o teor das condenações do Brasil perante a Corte IDH, o fato é que os julgados participaram da fundamentação apenas como forma de se dar ênfase à existência da violação de Direitos Humanos no âmbito interno, e não como construção significante acerca do conteúdo dos próprios direitos. Não se tenta delimitar o conteúdo dos direitos, limitando-se o STF a afirmar que eles estão sendo violados. 
Ou seja, as decisões da Corte Interamericana são utilizadas para chancelar o óbvio: existe violação de Direitos Humanos no cárcere. Mas resta o silêncio do Supremo sobre qual o conteúdo desses direitos, sobretudo no que tange às soluções que se fazem necessárias nesse contexto.

\section{RECURSO EXTRAORDINÁRIO 580.252/ MS}

O Recurso Extraordinário 580.252/MS é interessante para a análise aqui proposta, pois reconhece, novamente, as condições sub-humanas de execução da pena em presídio do Mato Grosso e, diante do fato, condena o Estado ao pagamento de danos morais ao detento.

O fato originário se refere a uma pessoa condenada a 20 (vinte) anos de reclusão pela prática de latrocínio, cujo cumprimento de pena se deu na penitenciária de Corumbá, MT. O condenado entrou com ação requerendo danos morais pelas condições as quais se viu exposto. Em primeiro grau o pedido foi indeferido. No Tribunal de Justiça do Estado do Mato Grosso reviu-se a decisão e condenou-se o Estado, com a seguinte ementa:

EMENTA - APELAÇÃO CÍVEL - AÇÃO DE INDENIZAÇÃO - DANO MORAL CARACTERIZADO - TEORIA DA RESERVA DO POSSÍVEL CONJUGADA COM O MÍNIMO EXISTENCIAL - PREQUESTIONAMENTO - MATÉRIA SUFICIENTEMENTE DEBATIDA E DISCUTIDA PELO ÓRGÃO COLEGIADO RECURSO PROVIDO. O Estado será responsabilizado a indenizar quando, por ato omissivo, tenha causado dano a particular, desde que comprovada a conduta culposa ou dolosa do ente federativo. Demonstrado que os problemas de superlotação e de falta de condições mínimas de saúde e higiene do estabelecimento penal (presídio) não foram sanados, após o decurso de um lapso temporal quando da formalização do laudo de vigilância sanitária, violando, por conseguinte, as disposições da Lei de Execução Penal, bem como a Convenção Interamericana de Direitos Humanos, está devidamente comprovada a conduta omissiva culposa do Estado (culpa administrativa). Não sendo assegurado o mínimo existencial, não há falar em aplicação da teoria da reserva do possível. Recurso provido (BRASIL, 2017).

O caso escolhido é interessante pois, muito embora o cerne da questão seja a execução da pena, ele traz como consequência a responsabilidade civil do Estado pela reparação dos danos morais oriundos da inserção em local sem as mínimas condições de humanidade. No caso em apreço, foi fixado o valor de R \$2.000,00 (dois mil reais) como quantum indenizatório. Após a decisão pelo TJMT, a procuradoria do Estado ingressou com embargos infringentes e conseguiu reverter a situação, sob o argumento de que a forma de investimento da Administração Pública está dentro do juízo de conveniência e oportunidade, e mais, que "uma vez reconhecido o direito do autor, pelo princípio da isonomia, todos os detentos deveriam ser indenizados, o que geraria um dispêndio vultuoso aos cofres do Estado" (BRASIL, STF, RE 580.252/MS, p. 4-5, inteiro teor).

A Defensoria Pública estadual, que representou o assistido, então interpôs o Recurso Extraordinário em comento, fazendo referência aos Direitos Humanos resguardados pela Convenção Americana e alegando, 
ademais, a responsabilidade do Estado pelas lesões causadas aos encarcerados:

[...] ofensa aos artigos $5^{\circ}$, III, X, XLIX; e 37º $\$ 6^{\circ}$, da Constituição, e também ao artigo $5^{\circ}$ do Pacto de São José da Costa Rica, asseverando, em suma, que (a) a submissão do recorrente e outros detentos na mesma penitenciária a tratamento desumano e degradante foi expressamente reconhecida pelo acórdão recorrido, o que lhe causa anormal sofrimento configurador de pena privativa de liberdade ocorre em penitenciária de dano moral indenizável; (b) é dever do Estado atender minimamente as condições carcerárias previstas em lei relativamente aos que estão sob sua custódia, inclusive no sentido de reeducá-los para o retorno à sociedade; (c) o próprio recorrido admite, publicamente, o caos do sistema prisional do Estado do Mato Grosso do Sul, tendo o Governador reeditado, por diversas vezes, o Decreto "E" n. 41, de 16/05/2005, no qual faz as considerações necessárias para decretar a "Situação de Emergência" dos Presídios em decorrência "do colapso do Sistema Penitenciário"; (d) o princípio da reserva do possível não pode ser abstratamente invocado, sob pena do Estado utilizar-se desse argumento para afastar sua responsabilidade em diversas áreas de sua atuação. Pede, assim, o provimento do recurso, para acolher o pedido formulado na demanda (BRASIL, STF, RE 580.252/ MS, p. 6-7, inteiro teor).

Embora negado inicialmente, por agravo interno o Recurso Extraordinário subiu, e nele foi reconhecida a seguinte repercussão geral:

Considerando que é dever do Estado, imposto pelo sistema normativo, manter em seus presídios os padrões mínimos de humanidade previstos no ordenamento jurídico, é de sua responsabilidade, nos termos do art. $37, \mathbb{\$} 6^{\circ}$, da Constituição, a obrigação de ressarcir os danos, inclusive morais, comprovadamente causados aos detentos em decorrência da falta ou insuficiência das condições legais de encarceramento.

A riqueza deste caso diz respeito à interlocução realizada com os parâmetros de cumprimento dos

tratados de Direitos Humanos. O Ministro Teori Zavascki, em seu voto, adverte:

[...] Não por outra razão, o Brasil, nos últimos 10 anos, foi seguidamente notificado pela Corte Internacional de Direitos Humanos (CIDH) para tomar medidas emergenciais em relação a pelo menos três presídios específicos, por conta de suas condições intoleráveis (Urso Branco, em Porto Velho/RO; Pedrinhas/MA; e Presídio Central, em Porto Alegre/RS). É significativa, ainda, a menção a excerto do Relatório Final produzido em 2009 por Comissão Parlamentar de Inquérito da Câmara dos Deputados, no qual se conclui que "a superlotação é talvez a mãe de todos os demais problemas do sistema carcerário. Celas superlotadas ocasionam insalubridade, doenças, motins, rebeliões, mortes, degradação da pessoa humana. A CPI encontrou homens amontoados como lixo humano em celas cheias, se revezando para dormir, ou dormindo em cima do vaso sanitário (fl. 247) ((BRASIL, STF, RE 580.252/ MS, p. 6-7, inteiro teor).

Outros ministros também trataram do assunto como fundamento para a condenação do Estado aos danos morais. Veja que a condenação dialoga com o Recurso Extraordinário anteriormente analisado, já que se o Poder Judiciário tem legitimidade para obrigar os Entes Federados a reformar e cuidar dos locais de cumprimento de pena, tem, por outro giro, o dever de condená-los em caso de não cumprimento espontâneo de sua obrigação. Para tanto, as decisões e determinações dos Pactos de Direitos humanos são indispensáveis, em um sentido de reforço positivo e recolocação das questóes relativas aos direitos pela dignidade no cumprimento das penas privativas de liberdade no Brasil. 


\section{AÇÃO DE DESCUMPRIMENTO DE PRECEITO FUNDAMENTAL 347}

A terceira ação selecionada para a análise trata da Ação de Descumprimento de Preceito Fundamental (ADPF) 347. Inicialmente é importante situar que esta é uma das ações típicas do controle concentrado de constitucionalidade presentes no ordenamento jurídico nacional, tendo por efeito direto da decisão a vinculação dos Poderes Executivo e Judiciário, assim como eficácia erga omnes. Estas características específicas já demonstram a importância da ação para a análise do artigo, já que a decisão final do procedimento será um marco regulatório a ser seguido em todas as controvérsias judiciais que perpassarem por tema correlato.

Mencionada ação foi protocolada junto ao Supremo Tribunal Federal (STF) no dia 27 de maio de 2015. O legitimado ativo foi Partido Socialismo e Liberdade (PSOL), sob o patrocínio da Clínica de Direitos Fundamentais da UERJ (Universidade do Estado do Rio de Janeiro), capitaneada pelo jurista Daniel Sarmento.

Há vários pedidos e requerimentos na ação, dentre os quais se destacam a determinação por parte do Poder Judiciário de cumprimento de funções institucionais típicas atinentes aos Poderes Executivo e Legislativo, como o descontingenciamento das verbas do FUNPEN e a construção de políticas públicas carcerária por parte do Distrito Federal, União e Estados-membro. Houve, ainda, pedido pela obrigatoriedade das audiências de custódia, que, embora não estejam positivadas no sistema processual penal nacional, estão previstas no Pacto de São José da Costa Rica. Por fim, a declaração do estado de coisas inconstitucional (ECI).

A declaração do ECI teria como consequência a adoção de providências concretas destinadas a sanar as gravíssimas lesões aos preceitos fundamentais da Constituição relacionados aos direitos dos encarcerados, a saber:

[...] o princípio da dignidade da pessoa humana (art. 1º, III CF) - como também inúmeros outros direitos fundamentais, como a vedação de tortura e de tratamento desumano ou degradante (art. 50, III), a proibição de sanções cruéis (art. 50, XLVII, "e"), a garantia de respeito à integridade física e moral do preso (art. $5^{\circ}$, XLIX), o direito de acesso à Justiça (art. $5^{\circ}, \mathrm{XXXV}$ ), o devido processo legal (art. $5^{\circ}$, LIV e LV), a presunção de inocência (art. $5^{\circ}$, LVII) e os direitos sociais à saúde, educação, trabalho e segurança (art. 6º) (BRASIL, 2015a, p. 16).

Todas as afrontas apontadas são decorrentes de condutas comissivas e/ou omissivas dos poderes públicos da União, dos Estados e do Distrito Federal. Na inicial, o procurador relembra que os revezes padecidos pelos encarcerados não são novidade. Ao contrário, são de amplo conhecimento dos poderes Legislativo, Executivo e Judiciário, e por tal razão uma ação comum (como as ações civis públicas) não teriam amplitude suficiente para respaldar todo o cenário nacional com relação às medidas necessário para salvaguarda dos direitos dos encarcerados em um sentido de manutenção e garantia de sua dignidade humana.

Ao traçar o fundamento fático do pedido, Sarmento (2015) descreve a atual situação prisional brasileira, 
enfatizando a existência de violações contumazes de Direitos Humanos constitucionalmente consagrados. Em referência à obra "Divina Comédia" de Dante Alighieri, o jurista compara o sistema carcerário brasileiro ao inferno dantesco. A primeira parte de sua exposição leva o título de "Inferno: o sistema prisional, a Constituição e o papel do STF”. O pequeno trecho a seguir nos mostra o cenário corriqueiro nas prisões e penitenciárias do Brasil

[...] celas superlotadas, imundas e insalubres, proliferação de doenças infectocontagiosas, comida intragável, temperaturas extremas, falta de água potável e de produtos higiênicos básicos. Homicídios, espancamentos, tortura e violência sexual contra os presos são frequentes, praticadas por outros detentos ou por agentes do próprio Estado. As instituições prisionais são comumente dominadas por facções criminosas, que impõem nas cadeias o seu reino de terror, às vezes com a cumplicidade do Poder Público. Faltam assistência judiciária adequada aos presos, acesso à educação, à saúde e ao trabalho. O controle estatal sobre o cumprimento das penas deixa muito a desejar e não é incomum que se encontrem, em mutirões carcerários, presos que já deveriam ter sido soltos há anos. Neste cenário revoltante, não é de se admirar a frequência com que ocorrem rebeliões e motins nas prisões, cada vez mais violentos. (BRASIL, 2015a, p. 2).

Mais adiante, aludindo ao "descalabro do sistema carcerário brasileiro" aponta ser "fato notório e inquestionável a gravidade das violações aos Direitos Humanos dos presos". Nesse momento, visando a amplificar a gravidade da situação, traz citação de decisões da Corte Interamericana que servem para ratificar o estado de emergência do sistema carcerário no Brasil:

A situação chegou ao ponto de motivar intervenções da Corte Interamericana de Direitos Humanos, que condenou o Estado brasileiro a cumprir medidas provisórias para garantir a erradicação das situações de risco e providenciar a proteção à vida e à integridade pessoal, psíquica e moral de pessoas privadas de liberdade em várias penitenciárias do país. Foi o caso do Centro Penitenciário Professor Aníbal Bruno, de Recife/PE, da Penitenciária Urso Branco, de Porto Velho/ RO, do Complexo do Tatuapé, de São Paulo/SP,11 da Penitenciária Dr. Sebastião Martins Silveira, de Araraquara/ SP, e do Complexo de Pedrinhas, de São Luiz/MA. A Comissão Interamericana, por sua vez, concedeu medidas cautelares contra o Estado Brasileiro para salvaguardar a vida e a integridade pessoal dos internos do Presídio Central de Porto Alegre/ RS (BRASIL, 2015, p. 4).

Muito embora seja fato concreto as condenações mencionadas, ainda assim o país se mostra reticente quanto a solucionar o grave problema apresentado. Exatamente por isso, pelo fato de o Direito interno e os órgãos de poder oficial não estarem conseguindo reverter a situação caótica, pensa-se na importância do Direito Internacional levado a efeito na Corte Interamericana de Direitos Humanos. Neste sentido, vale lembrar os exemplos trazidos por Sarmento na inicial apontada, o que se fará a seguir.

\section{A jurisprudência da Corte Interamericana de Direitos Humanos e sua utilização como argumento para o deferimento da ação}

Ao todo, a petição inicial citou cinco cases contra o Estado brasileiro perante a Corte IDH. Entretanto, a despeito da importância de se fazer menção às condenações sofridas pelo Brasil, pode-se afirmar que esse recurso 
foi utilizado mais como argumento de persuasão do que como fundamento para a construção dos Direitos Humanos do encarcerado. Indicou-se simplesmente que o Brasil foi (e pode voltar a ser) condenado em âmbito internacional pela Corte IDH, em razão das mazelas no sistema penitenciário nacional. Deste modo, a jurisprudência da Corte não foi empregada no sentido de se demandar a fixação de um conteúdo mínimo dos direitos dos presos.

Desta sorte, a petição inicial chega a tecer comentários sobre o caso Barreto Leiva v. Venezuela, no qual foi estabelecido que as prisões processuais devem ter caráter "excepcional, limitado pelos princípios da legalidade, presunção de inocência, necessidade e proporcionalidade, de acordo com o que seja estritamente necessário em uma sociedade democrática”.

Entretanto, é somente o intento de consolidar uma medida concreta quanto ao problema estrutural da superlotação que oferece destaque às decisões da Corte IDH, mais especificamente no que diz respeito à implantação das audiências de apresentação e custódia das pessoas privadas de liberdade em sede provisória. Quanto ao assunto, é importante destacar que ele advém da Convenção Americana de Direitos Humanos quando menciona no art. 7, item 5 que "toda pessoa presa, detida ou retida deve ser conduzida, sem demora, à presença de um juiz ou outra autoridade autorizada por lei a exercer funções judiciais [...]”. A partir desta norma, associada a outras, a Corte IDH passou a firmar entendimento garantista em relação aos encarcerados.

Assim, a petição menciona os casos mais relevantes da Corte sobre a audiência de custódia, a saber, o caso Acosta Calderón vs. Equador, o caso Chaparro Álvarez e Lapo Iñiguez vs. Equador, e o caso Cabrera Garcia e Montiel Flores vs. México. O nível de detalhamento dessas decisões não é irrelevante para a matéria em questão, já que permitiu discutir, nesse contexto, se o prazo de cinco dias seria incompatível com a exigência de uma apresentação "sem demora" do preso à autoridade judicial.

No geral, é possível considerar a perda de uma oportunidade na avaliação feita a respeito da superpopulação carcerária, assim como quando passa a abordar com maior detalhamento as violações de direitos ocorridas no cárcere (v.g. acesso à justiça, direito à assistência material mínima para alimentação, vestuário, higiene, etc., direito à saúde, à igualdade de gênero, respeito à orientação sexual, e proibição da tortura e da imposição de sanções ilegítimas), uma vez que fica omitida uma abundante produção da Corte IDH, que poderia servir de fundamento aqui (cf. BRASIL, 2015, pp. 27-51).

Por fim, Sarmento conclui sua petição dizendo que o Brasil, neste ponto, vive num verdadeiro Estado de Coisas Inconstitucional caracterizado pela existência da grave e massiva violação de direitos, decorrentes de falhas estruturais em políticas públicas, as quais demandam muitas vezes soluções complexas dos tribunais. Em tal hipótese, o papel de guardião da Constituição exige uma postura diferenciada, sob pena de frustração dos direitos fundamentais e inefetividade da Constituição Federal. 


\section{Inexpressividade da jurisprudência da Corte IDH na decisão do STF}

Quanto ao decidido, em sede liminar, o Relator Ministro Marco Aurélio de Mello reconhece em seu voto a importância dos Direitos Humanos assegurados por convenções internacionais às pessoas presas, dentre os quais o Pacto de San José da Costa Rica (BRASIL, 2016b, pp. 1-46). Todavia, não já qualquer referência a respeito da atuação da Corte IDH naquilo que interessa aos direitos que teriam sido violados na situação apreciada pelo STF.

Assim, o Ministro faz alusão à existência da Corte IDH, mas sem qualquer aprofundamento quanto ao conteúdo de suas decisões.

A leitura do julgado revela que as citações das decisões da Corte IDH foram escassas e extremamente genéricas. Quanto ao assunto, faziam referência não aos direitos dos encarcerados, mas apenas às sanções recebidas pelo Brasil em âmbito internacional.

Interessante notar que os Ministros, de forma unânime, entenderam que a situação carcerária nacional constitui pena cruel, degradante e desumana. Ademais, consideraram que a situação de superlotação é injustificável, que o Estado é o grande responsável por isso, mormente o Executivo, pois não dá efetividade ao que determina o Ordenamento. Não obstante isso, o fato é que os Ministros não desenvolveram, pelo menos em sede da decisão cautelar, quais seriam os direitos violados mais concretamente. Fazem, em todos os votos, referência ao "mínimo existencial", mas não dizem quais direitos comporiam esse mínimo existencial. Com isso, a única referência efetiva da jurisprudência da Corte IDH se deu quanto às audiências de apresentação do preso perante o juiz.

Talvez a situação do cárcere no Brasil seja tão grotesca, que possa parecer desnecessário traçar quais são os direitos violados no estado de coisas inconstitucional. Ainda que houvessem se pronunciado em sede meramente cautelar, os magistrados pecaram na oportunidade de substanciar esses direitos e de apontar concretamente quais os direitos violados. Em verdade, a abstração dos votos foi enorme, dando a sensação de que se decidiu sem resolver coisa alguma.

\section{CONCLUSÃO}

A presente pesquisa teve por objetivo avaliar a influência das decisões da Corte Interamericana de Direitos Humanos no âmbito do Supremo Tribunal Federal. Ela partiu da hipótese de que a influência da Corte IDH é quase inexpressiva em comparação com a sua importância no cenário de proteção aos Direitos Humanos. Para testar essa hipótese, foi escolhido o tema da execução criminal, uma a área sensível para os Direitos Humanos 
no Brasil, em relação à qual o país tem recebido diversas condenações e advertências no plano internacional de proteção aos Direitos Humanos.

Em uma pesquisa preliminar, foram selecionados os julgamentos do STF que fazem referência à Corte IDH no tratamento do encarcerado. Procedeu-se, então, a uma análise qualitativa das três decisões mais expressivas, a Ação de Descumprimento de Preceito Fundamental 347, o Recurso Extraordinário 592.581/RS e o Recurso Extraordinário 580.252/MS. Ao final, foi constatado que, não obstante as decisões da Corte IDH tratarem de maneira expressa e detalhada de problemas relacionados ao cárcere, as diretivas fixadas pela Corte Internacional não chegaram a ser consideradas pelos julgados brasileiros, o que indica a falta de abertura do STF para tais decisões em termos de concreção dos direitos fundamentais.

Com isso, espera-se chamar atenção para o atual isolamento da corte constitucional brasileira, que muito pode avançar na matéria de proteção dos Direitos Humanos no cárcere, caso passe a dialogar com a jurisprudência já consolidada da Corte Interamericana de Direitos Humanos.

\title{
DIALOGUE OF COURTS: THE INFLUENCE OF THE INTER-AMERICAN COURT OF HUMAN RIGHTS IN MATTERS OF CRIMINAL EXECUTION IN THE FEDERAL SUPREME COURT
}

\begin{abstract}
The article seeks to evaluate the influence of the decisions of the Inter-American Court of Human Rights (IACHR) in the Brazilian Supreme Court (STF). The topic of analysis was criminal execution, an area in which Brazil has received condemnations and advertences from international organizations. The aim was to demonstrate the need for a greater dialogue between the Supreme Court and the Inter-American Court, whose production in this area has much to contribute to the advancement of the protection of human rights in Brazilian prisons. The research was bibliographical and exploratory, and the method of approach was the inductive one. The collection of jurisprudence followed quantitative and qualitative standards.
\end{abstract}

Keywords: Inter-American Court of Human Rights; Supreme Court; dialog between courts; prision; prisoner; Human rights; fundamental rights; jurisprudence. 


\section{REFERENCIAS}

BRASIL, Presidência da República. Decreto no 678, de 6 de novembro de 1992. Promulga a Convenção Americana sobre Direitos Humanos (Pacto de São José da Costa Rica), de 22 de novembro de 1969. Legislação. Brasília, DF, 6 de novembro de 1992. Disponível em: <http://www.planalto.gov.br/ccivil_03/decreto/d0678.htm>.Acesso em: 1 jul. 2017.

BRASIL. Supremo Tribunal Federal. Embargos de declaração nos Embargos de declaração no Agravo regimental no Agravo de Instrumento no 769637. EMBTE.(S): CESAR ALBERTO CABRAL E CASTRO. EMBDO.(A/S) : MINISTÉRIO PÚBLICO DO ESTADO DE MINAS GERAIS. Relator: Relator(a): Min. CELSO DE MELLO. Brasília, DF, 26 de junho de 2013a. Diário de Justiça Eletronico. Brasília, 15 out. 2013. Disponível em: <http://www.stf.jus.br/portal/processo/verProcessoAndamento.asp?numero=769637\&classe=AI-AgR-EDED\&codigoClasse=0 \&origem=JUR\&recurso=0\&tipoJulgamento=M $>$. Acesso em: 03 ago. 2017. (2013a).

BRASIL. Supremo Tribunal Federal. Medida Cautelar em Ação de Descumprimento de Preceito Fundamental no 347. REQTE.(S): PARTIDO SOCIALISMO E LIBERDADE - PSOL. Relator: Relator(a): Min. MARCO AURÉLIO. Brasília, DF, 09 de setembro de 2015. Diário de Justiça Eletronico. Brasília, 19 fev. 2016. Disponível em:

<http://www.stf.jus.br/portal/jurisprudencia/listarJurisprudencia.asp?s 1=(347.NUME.+OU+347.ACMS.)\&ba se=baseAcordaos\&url=http://tinyurl.com/j4wnalu>. Acesso em: 03 ago. 2017. (2016a).

BRASIL. Supremo Tribunal Federal. Recurso Extraordinário no 592581. RECTE.(S): MINISTÉRIO PÚBLICO DO ESTADO DO RIO GRANDE DO SUL. RECDO.(A/S): ESTADO DO RIO GRANDE DO SUL. Relator: Relator(a): Min. RICARDO LEWANDOWSKI. Brasília, DF, 13 de agosto de 2015. Diário de Justiça Eletronico. Brasília, $01 \quad$ fev. $2016 . \quad$ Disponível em: <http://www.stf.jus.br/portal/jurisprudencia/listarJurisprudencia.asp?s1=(592581.NUME.+OU+592581.ACM S.) \&base=baseAcordaos\&url=http://tinyurl.com/h9p2p6n>. Acesso em: 03 ago. 2017. (2016b).

BRASIL. Supremo Tribunal Federal. Recurso Extraordinário no 580.252, julg. 16/02/2017. Relator: Relator(a): Min. Alexandre de Morais. Disponível em: <http://www.stf.jus.br/portal/jurisprudencia/listarJurisprudencia.asp?s1=\%28RE\%24\%2ESCLA\%2E+E+58025 2\%2ENUME\%2E\%29+OU+\%28RE\%2EACMS\%2E+ADJ2+580252\%2EACMS\%2E\%29\&base=baseAcordaos 
\&url=http://tinyurl.com/ahmcrul>Acesso em: 15 mar. 2018.

BRASIL. Supremo Tribunal Federal. Embargos declaratórios no habeas corpus no 126292. EMBTE.(S): MARCIO RODRIGUES DANTAS. EMBDO. (A/S): RELATOR DO HC No 313.021 DO SUPERIOR TRIBUNAL DE JUSTIÇA. Relator: Relator(a): Min. TEORI ZAVASCKI. Brasília, DF, 02 de setembro de 2016c. Diário de Justiça Eletronico. Brasília, 07 fev. 2017. Disponível em: <http://www.stf.jus.br/portal/jurisprudencia/listarJurisprudencia.asp?s1=(126292.NUME.+OU+126292.ACM S.)\&base=baseAcordaos\&url=http://tinyurl.com/jukvr93>. Acesso em: 03 ago. 2017.

BRASIL. Supremo Tribunal Federal. Ação Penal Originária no 470. Relator: RELATOR: MIN. JOAQUIM BARBOSA. Brasília, DF, 17 de dezembro de 2012. Diário de Justiça Eletronico. Brasília, 22 abr. 2013. Disponível em: <http://www.stf.jus.br/portal/ap470/InteiroTeor_AP470.pdf>. Acesso em: 03 ago. 2017. (2013b).

BRASIL. Supremo Tribunal Federal. Habeas Corpus n 115539. PACTE(S): ELITON ALVES ALFAIA. COATOR(A/S)(ES) : SUPERIOR TRIBUNAL DE JUSTIÇA. Relator: Relator(a): Min. CELSO DE MELLO. Brasília, DF, 17 de setembro de 2013. Diário de Justiça Eletronico. Brasília, 16 set 2013. Disponível em: <http://www.stf.jus.br/portal/processo/verProcessoAndamento.asp?numero=115539\&classe=HC\&codigoCla sse $=0$ \&origem $=J U R \&$ recurso=0\&tipoJulgamento=M $>$. Acesso em: 03 ago. 2017. (2013c).

BRASIL. Supremo Tribunal Federal. Habeas Corpus no 110185. PACTE(S): ADEMILSON MOREIRA DE ALMEIDA. COATOR(A/S)(ES) : SUPERIOR TRIBUNAL MILITAR. Relator: Relator(a): Min. CELSO DE MELLO. Brasília, DF, 14 de maio de 2013. Diário de Justiça Eletronico. Brasília, 29 out. 2014. Disponível em: <http://www.stf.jus.br/portal/jurisprudencia/listarJurisprudencia.asp?s1=(110185.NUME.+OU+1 10185.ACM S.)\&base=baseAcordaos\&url=http://tinyurl.com/j8chhy3>. Acesso em: 03 ago. 2017. (2013d).

BRASIL. Supremo Tribunal Federal. Habeas Corpus no 110237. PACTE.(S) : CARLOS NUNES DE AZEVEDO. COATOR(A/S)(ES) : SUPERIOR TRIBUNAL MILITAR. Relator: Relator(a): Min. CELSO DE MELLO. Brasília, DF, 19 de fevereiro de 2013. Diário de Justiça Eletronico. Brasília, 01 mar. 2013. Disponível em: $<$ http://redir.stf.jus.br/paginadorpub/paginador.jsp?docTP=TP\&docID=3456276>. Acesso em: 03 ago. 2017. (2013e).

BRASIL, Supremo Tribunal Federal. Ação de Descumprimento de Preceito Fundamental no 347. Peticionante: 
Partido Socialismo e Liberdade. Petição Inicial. 2015.

LINÃRES, Sebastián. El diálogo democrático entre las cortes y las instituiciones representativas. Revista Mexicana de Sociología 70, n. 3 (julio-septiembre, 2008, p. 487- 539.

NIÑO, Carlos Santiago. Ética y derechos humanos: un ensayo de fundamentación. 2. ed. Buenos Aires: Editorial Astrea de Alfredo y Ricardo Depalma S.r.l., 1989.

RAMOS, André de Carvalho. Teoria Geral dos Direitos Humanos na ordem internacional. 6. ed. São Paulo: Saraiva, 2016.

ORGANIZAÇÃO DOS ESTADOS AMERICANOS, Corte interamericana de Direitos Humanos. Personas privadas de libertad: Cuadernillo de Jurisprudencia de la Corte Interamericana de Derechos Humanos No 9. San José, 2014. 99 p. Disponível em: <http://www.corteidh.or.cr/sitios/libros/todos/docs/privados9.pdf>. Acesso em: 26 jul. 2017.

SARMENTO, Daniel. O Direito Constitucional e o Direito Internacional. In: ALVES, Cândice Lisbôa (org). Vulnerabilidades e invisibilidades: desafios contemporâneos para a concretização dos Direitos Humanos. Belo Horizonte: Arraes Editores, 2015.

Trabalho enviado em 09 de agosto de 2018

Aceito em 03 de setembro de 2018 